\title{
Anisomycin and the reconsolidation hypothesis
}

\author{
Jerry W. Rudy, ${ }^{1}$ Joseph C. Biedenkapp, Jeannine Moineau, and Kevin Bolding \\ Center for Neuroscience, Department of Psychology, University of Colorado, Boulder, Colorado 80309, USA
}

For over 30 years researchers have suspected that the very act of retrieving a memory places it in a labile state and leaves it vulnerable to subsequent challenges that affect the brain. Misanin et al. (1968) provided the initial empirical basis for this claim when they reported that electroconvulsive shock (ECS) presented immediately following a brief presentation of a fear-conditioned CS produced retrograde amnesia for the fear memory, whereas ECS alone had no effect on the fear memory. Thus, a memory in an active state appeared to be more vulnerable to the effects of an amnesia-producing event than when it is in an inactive state (Lewis 1979).

This basic empirical claim was followed by controversy over both its repeatability and generality (e.g., Dawson and McGaugh 1969) and its proper theoretical interpretation: Was the resulting amnesia due to the destruction of the memory trace or did the amnestic agent just render the memory temporarily inaccessible (see Miller and Springer 1973)? Perhaps for these reasons research interest in these phenomena lay dormant until fairly recently.

Interest in the fate of reactivated memories dramatically increased with the recent work of Nader and his colleagues (Nader et al. 2000; Debiec et al. 2002; Nader 2003) and Przybyslawski and Sara (1997). In their seminal paper, Nader et al. (2000) reactivated an auditory-cue fear memory and then injected the antibiotic, anisomycin, a protein synthesis inhibitor, or vehicle into the basolateral region of the amygdala (BLA). Subsequent retesting with the CS revealed that anisomycin produced amnesia for the reactivated fear memory. Anisomycin given without reactivating the memory had no effect.

\section{The reconsolidation hypothesis}

Nader et al.'s (2000) results were interesting, but what caught the attention of the field was the bold new reconsolidation hypothesis that accompanied the finding - the retrieval of a memory places it in a labile state that requires de novo protein synthesis for its restorage. The intriguing implications of this idea were that retrieving the memory in some way uncoupled the synapses holding the memory so that they had to be rebuilt. This rebuilding, like consolidation, required the synthesis of new protein. The memory had to be reconsolidated.

This is truly a novel hypothesis. Note the theoretical controversy generated by the initial discovery that reactivated memories could be disrupted was largely about whether the amnestic agent destroyed the memory or made it temporarily inaccessible (see Miller and Springer 1973). In this debate it was assumed that the agent itself caused the amnesia. In essence, however, the new reconsolidation hypothesis supposes that the act of retrieval itself is an amnestic event. "... some property of retrieval may destabilize the structural changes such that they now have to be reconsolidated with the aid of new protein (Nader et al. 2000)." The influential paper by Nader (2003) proposed that retrieved memories are returned to an active state that requires protein synthesis dependent mechanisms to return to the inactive state (see legend, Fig. 1 in Nader 2003).

\footnotetext{
'Corresponding author.

E-mail jrudy@psych.colorado.edu; fax (303) 492-2967.

Article and publication are at http://www.learnmem.org/cgi/doi/10.1101/ Im.157806.
}

Note that according to this theory anisomycin's role in this phenomenon is that it uncovers retrieval-induced amnesia that otherwise would go unnoticed. It is not the cause of the amnesia. Because anisomycin is known to inhibit the synthesis of new protein, the argument is that it disrupted the synthesis of the proteins required to prevent the potential amnesia caused by retrieving the memory. The implication of this hypothesis is that some retrieved memories may have to be rebuilt.

Given its originality and its implications for the cellular/ molecular basis of memory, it is not surprising that the reconsolidation hypothesis has rightfully captured the attention and imagination of contemporary neurobiologists. It is also not surprising that the same issues that surrounded the initial reports in the $60 \mathrm{~s}$ and 70s have re-emerged in the contemporary literature. What are the boundary conditions of the phenomenon? Can it be reliably reproduced? Is the effect of anisomycin on reactivated memories temporary or permanent-is the memory lost or just inaccessible?

\section{Power and colleagues report that amnesia produced by anisomycin can be temporary}

Against this background, the report by Power et al. (2006) is important because it again raises the question of how to interpret the amnesia produced when a reactivated memory is followed by a challenge, in this case anisomycin. Is the amnestic effect of anisomycin permanent or temporary? In a well-designed study, the authors first trained rats on an inhibitory avoidance paradigm. These animals were subsequently assigned to three conditions. Six hours following training two groups received a retention test that also can be considered to reactivate the memory. Immediately following the retention/reactivation trial, either anisomycin or vehicle was injected bilaterally into the dorsal hippocampus. Rats in the third condition did not experience the retention test but they were injected with anisomycin. The next day rats in all conditions were tested. The results were quite clear, only when given after reactivation did anisomycin produce amnesia for the avoidance memory. These results established that the first retention test put the avoidance memory in a labile state that made it vulnerable to some property of anisomycin. The authors then asked if the memory would recover. They repeated their original experiment, but in this experiment the second retention test was given either $1 \mathrm{~d}$ or $6 \mathrm{~d}$ after the reactivation. The results again were clear. As in the first experiment, rats treated with anisomycin displayed amnesia when the second test was a day later, but if the interval was $6 \mathrm{~d}$ there was no amnesia. The memory recovered. Power and colleagues' data thus join other recent reports (Fischer et al. 2004; Lattal and Abel 2004) indicating that anisomycin can produce amnesia for a reactivated memory by temporarily preventing access to a reactivated memory.

\section{Anisomycin: An amnestic agent}

The Power et al.'s (2006) result highlights the general importance of including a control experiment that tests for recovery. However, its significance goes beyond this point. Such a result also means that, in addition to its assumed ability to block the syn- 
thesis of proteins needed to restabilize the memory, anisomycin has other properties (side effects) that can negatively impact on neural circuits supporting a recently activated memory.

The use of antibiotics, such as anisomycin, as protein synthesis inhibitors in memory research, of course, has a long history that begins in the 1960s (Flexner et al. 1963; for review, see Davis and Squire 1984). There was never any doubt that antibiotics could block protein synthesis or that they could produce amnesia. However, there also was never any clear agreement that the associated amnesia was due to antibiotics blocking protein synthesis (Barraco and Stettner 1976; Martinez et al. 1981; but see Davis and Squire 1984). Yet, in the modern era, it is almost axiomatic that if anisomycin produces amnesia it does so by blocking protein synthesis, and that the memory in question depends on the synthesis of new protein for its consolidation or reconsolidation. Here we are simply echoing the same point recently made by Routtenberg and Rekart (2005).

There are recent reports that anisomycin permanently disrupts reactivated memories. In one notable example, Duvarci and Nader (2004) injected anisomycin into the BLA following the reactivation of an auditory-cue fear memory. They found no evidence that the lost memory either spontaneously recovered or that it could be reinstated by a reminder foot shock. It is, of course, impossible to prove that a lost memory will never recover. Nevertheless, for the sake of argument, we will stipulate in this case that the amnesia produced by anisomycin is permanent. Because anisomycin is a protein synthesis inhibitor, one is naturally inclined to conclude that its permanent effects are due to it inhibiting protein synthesis needed to reconsolidate the memory.

Given we know that when anisomycin is injected into the brain it can produce temporary amnesia for reinstated memories (Power et al. 2006), then we also know that anisomycin has unspecified properties that significantly alter the neural circuits supporting the memory. So, why should one now be compelled to believe that anisomycin produces permanent amnesia because it blocked the synthesis of new proteins needed to reconsolidate the memory? Why is it not likely that, under some conditions, anisomycin itself will permanently alter the neurons in the memory circuit and produce amnesia? One condition might be the location of the memory. For example, the hippocampus is a large structure and the memory trace might be distributed throughout its longitudinal axis. In contrast, the basolateral region of the amygdala is small and the memory trace may be far more localized. So, it is possible that anisomycin injected into the BLA may be far more devastating to the neural circuit supporting the memory than would be the case when it is injected into a subregion of the hippocampus.

In typical reconsolidation studies (e.g., Duvarci and Nader 2004; Power et al. 2006) anisomycin produces amnesia for the target memory if it is administered shortly after the memory is placed in the active state. It has no effect if it is given when the memory is not active. This is an important control observation because it establishes that the memory must be in the active state to be influenced by anisomycin. However, this finding does not speak to the mechanism of anisomycin's effect-whether it blocks protein synthesis or disrupts neural circuits. It just says that the memory must be active to be disrupted. Active neuronal circuits just might be especially sensitive to the nonspecific amnestic properties of anisomycin.

\section{Anisomycin can be an apoptotic agent}

In developing the idea that anisomycin may have amnestic properties beyond its ability to inhibit protein synthesis, we have been vague about just what these properties might be. Routten- berg and Rekart (2005), in their recent challenge to the basic premise that long-term memories require the generation of new protein, provided a litany of possible ways that anisomycin might be amnestic. In addition, we note that it should give memory researchers considerable concern to know that anisomycin is used in cancer research to study apoptosis (e.g., Curtin and Cotter 2002; Stadheim and Kucera 2002). Apoptosis is a genetically programmed cell death that can be triggered by both extracellular and intracellular events that initiate at least one of several molecular cascades that lead to fragmentation of DNA in the nucleus (see Adams 2003).

Anisomycin is a ribotoxin that is known to cause apoptosis (Iordanov et al. 1997, 1998). It does so by binding to the $28 \mathrm{~S}$ subunit of an actively translating ribosome to cause the inhibition of peptide bond formation and thus translational elongation (Iordanov et al. 1997, 1998). This activates stress-activated protein kinases (SAPKs) and/or cJun NH2-terminal kinases (JNKs) that begin at least one of the apoptotic cascades (Iordanov et al. 1997). It is interesting to note that Iordanov et al. (1997) also observed in cell cultures that the apoptotic cascade produced by anisomycin occurs in advance of its ability to inhibit protein synthesis. For example, they report that a dose of anisomycin that causes $50 \%$ maximal activation of SAPKs/JNKs only produces translational inhibition at $10 \%$ of its maximum. This finding suggests that messengers known to be involved in apoptosis are activated before there is significant protein synthesis inhibition.

Apoptosis may or may not be the cause of anisomycininduced amnesia. However, if anisomycin does produce significant apoptosis, this would be a major problem for the proteinsynthesis inhibition hypothesis. That protein synthesis was blocked would be irrelevant if the neurons are dead.

As noted, the reconsolidation interpretation of the vulnerability of reactivated memories has two assumptions: (1) Memory retrieval initiates synaptic/cellular activity that itself unbinds synaptic connections, and (2) the reconstruction of the memory trace requires the synthesis of new protein. These two hypotheses are not logically linked. The first assumption can be true and the second false. If the initial consolidation of memories can be mediated by post-translational mechanisms (Routtenberg and Rekart 2005), then it is possible that reactivated memories can be reconsolidated by similar mechanisms. Our cautionary comments about anisomycin question the second assumption, but may have no direct bearing on the first.

\section{Reconsolidation: A theory or collection of empirical observations?}

It is important to understand the fate of reactivated memories. Thus, it may be unfortunate that the term reconsolidation has come to represent both a particular theory (reactivated memories need new protein to restabilize) and a collection of empirical phenomena (retrieved memories are especially sensitive to posttrial manipulations). This is because it implies that all the empirical phenomena may have a single theoretical interpretation explanation. Researchers should be aware that the term reconsolidation has both theoretical and empirical meaning and use it only as a theoretical concept.

\section{Conclusions}

The renewed interest in the fate and vulnerability of reactivated memories is an exciting and potentially important chapter in the study of the neurobiology of memory. Our commentary makes four points that we hope will contribute to this topic: (1) The reconsolidation hypothesis-that reactivated memories require

\section{Learning \& Memory \\ www.learnmem.org}


new protein to restabilize is fundamentally different from the early interpretation that the retrieval of a memory makes it vulnerable to the effects of a subsequent event; (2) anisomycin has unspecified effects that can produce temporary amnesia for a reactivated memory and they also could be responsible for any permanent effects that anisomycin produces; (3) anisomycin can be apoptotic, and if this is true in the neural population supporting the memory, one cannot attribute its permanent effects to its ability to block protein synthesis; and (4) researchers should use the term reconsolidation as a theoretical and not use it to refer to an empirical observation.

\section{References}

Adams, J.M. 2003. Ways of dying: Multiple pathways to apoptosis. Genes \& Dev. 17: 2481-2495.

Barraco, R.A. and Stettner, L.J. 1976. Antibiotics and memory. Psychol. Bull. 83: 242-302.

Curtin, J.F. and Cotter, T.G. 2002. Anisomycin activates JNK and sensitises DU 145 prostate carcinoma cells to Fas mediated apoptosis. Br. J. Cancer 87: 1188-1194.

Davis, H.P. and Squire, L.R. 1984. Protein synthesis and memory: A review. Psychol. Bull. 96: 518-559.

Dawson, R.G. and McGaugh, J.L. 1969. Electroconvulsive shock effects on a reactivated memory trace: Further examination. Science 166: $525-527$.

Debiec, J., LeDoux, J.E., and Nader, K. 2002. Cellular and systems reconsolidation in the hippocampus. Neuron 36: 527-538.

Duvarci, S. and Nader, K. 2004. Characterization of fear memory reconsolidation. J. Neurosci. 24: 9269-9275.

Fischer, A., Sananbenesi, F., Schrick, C., Speiss, J., and Radulovic, J. 2004. Distinct roles of hippocampal de novo protein synthesis and actin rearrangement in extinction of contextual fear. J. Neurosci. 24: 1962-1966.

Flexner, J.B., Flexner, L.B., and Stellar, E. 1963. Memory in mice as affected by intracerebral puromycin. Science 141: 57-59.
Iordanov, M.S., Pribnow, D., Magun, J.L., Dinh, T.H., Pearson, J.A., Chen, S.L., and Magun, B.E. 1997. Ribotoxic stress response: Activation of the stress-activated protein kinase JNK1 by inhibitors of the peptidyl transferase reaction and by sequence-specific RNA damage to the $\alpha$-sarcin/ricin loop in the 28S rRNA. Mol. Cell. Biol. 17: 3373-3381.

Iordanov, M.S., Pribnow, D., Magun, J.L., Dinh, T.H., Pearson, J.A., and Magun, B.E. 1998. Ultraviolet radiation triggers the ribotoxic stress response in mammalian cells. J. Biol. Chem. 273: 15794-15803.

Lattal, K.M. and Abel T. 2004. Behavioral impairments caused by injections of the protein synthesis inhibitor anisomycin after contextual retrieval reverse with time. Proc. Natl. Acad. Sci. 101: $4667-4672$.

Lewis, D.J. 1979. Psychobiology of active and inactive memory. Psychol. Bull. 86: 1054-1083.

Martinez Jr., J.L., Jensen, R.A., and McGaugh, J.L. 1981. Attenuation of experimentally-induced amnesia. Prog. Neurobiol. 16: 155-186.

Miller, R.R. and Springer, A.D. 1973. Amnesia consolidation and retrieval. Psychol. Rev. 80: 69-79.

Misanin, J.R., Miller, R.R., and Lewis, D.J. 1968. Retrograde amnesia produced by electroconvulsive shock after reactivation of a consolidated memory trace. Science 160: 554-558.

Nader, K. 2003. Memory traces unbound. Trends Neurosci. 26: 65-72.

Nader, K., Schafe, G.E., and Le Doux, J.E. 2000. Fear memories require protein synthesis in the amygdala for reconsolidation after retrieval. Nature 406: 722-726.

Power, A.E., Berlau, D.J., McGaugh, J.L., and Steward, O. 2006. Anisomycin infused into the hippocampus fails to block "reconsolidation" but impairs extinction: The role of re-exposure duration. Learn. Mem. (this issue).

Przybyslawski, J. and Sara, S.J. 1997. Reconsolidation of memory after its reactivation. Behav. Brain Res. 84: 241-246.

Routtenberg, A. and Rekart, J. 2005. Post-translational protein modifications as the substrate for long-lasting memory. Trends Neurosci. 28: 12-19.

Stadheim, T.A. and Kucera, G.L. 2002. c-Jun N-terminal kinase/stress-activated protein kinase (JNK/SAPK) is required for mitoxantrone- and anisomycin-induced apoptosis in HL-60 cells. Leuk. Res. 26: 55-65. 


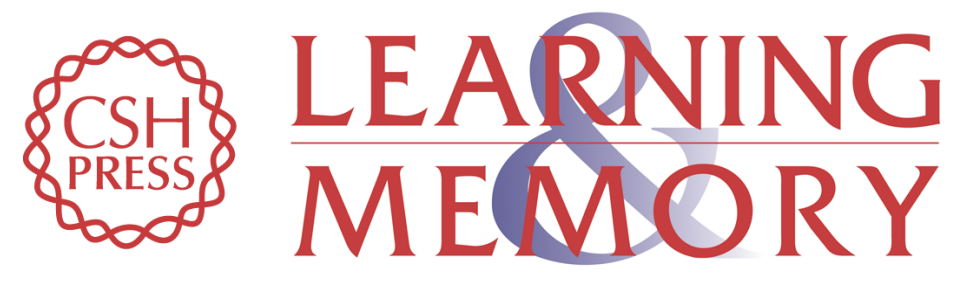

\section{Anisomycin and the reconsolidation hypothesis}

Jerry W. Rudy, Joseph C. Biedenkapp, Jeannine Moineau, et al.

Learn. Mem. 2006, 13:

Access the most recent version at doi:10.1101//m.157806

References This article cites 21 articles, 9 of which can be accessed free at: http://learnmem.cshlp.org/content/13/1/1.full.html\#ref-list-1

License

Email Alerting Receive free email alerts when new articles cite this article - sign up in the box at the Service top right corner of the article or click here. 